\title{
$15-16 \mid 2020$
}

69. Jahrgang

5. August 2020

S. 569-660

PVSt 6791

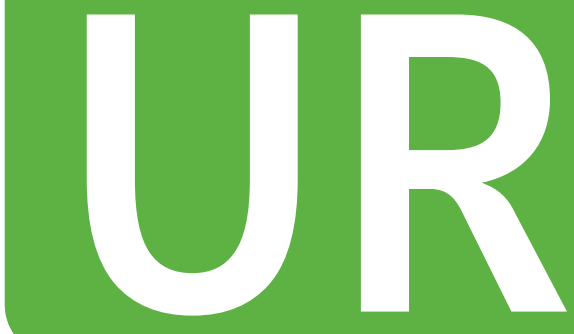

\section{UmsatzsteuerRundschau}

Zeitschrift für die gesamte

Umsatzsteuerpraxis

Herausgegeben in Verbindung mit dem UmsatzsteuerForum e.V.

umsatzsteuerrecht.de

Fachbeirat: RA/StB Prof. Dr. Hans Nieskens · Prof. Dr. Markus Achatz · Prof. Dr. Joachim Englisch PräsLfSt Dipl.-Fw. Stephan Filtzinger · Vors. RiBFH Prof. Dr. Bernd Heuermann · Richter am FG Dr. Martin Kemper · RA/FAStR/WP/StB Dirk Rose · RAin Regine Schluckebier · StB Dipl.-Fw. M.B.L. Jürgen Scholz $\cdot$ MinDirig. a.D. Werner Widmann

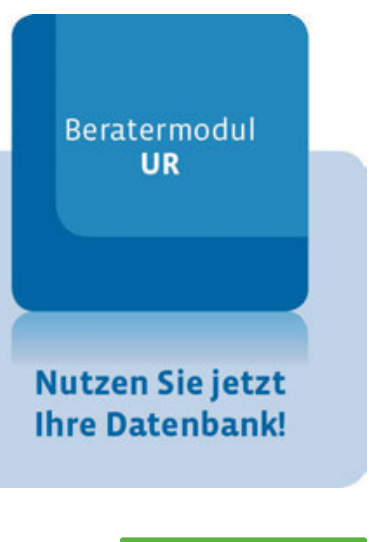

Festheft für Bernd Heuermann
Laudatio > Wolfgang Spindler - Bernd Heuermann zum Abschied aus dem

Bundesfinanzhof 569

Aufsätze > Peter Brandis - Betriebsvorrichtung und Bauleistung 571

Hans-Hermann Heidner - Die Gemeinnützigkeitsrechtsprechung des

V. Senats

Monika Jachmann-Michel - Nachträgliche Anschaffungskosten bei

§ 17 EStG im Wandel der Zeit

Harald Jatzke - Die Entstehung der Zollschuld und der Einfuhrumsatzsteuer bei zollrechtlichen Pflichtverstößen

Hanno Kube - Der Grundsatz der steuerlichen Neutralität in der Umsatzsteuer - Tragende Strukturen und ein aktueller Fall

Hans-Friedrich Lange - Gewährung des Vorsteuerabzugs aufgrund von Vertrauensschutz nur im Billigkeitsverfahren?

Gerhard Michel - Die Steuerfreiheit von Leistungen im Sozialbereich

Hans Nieskens - Immer Ärger mit der Bildung 2.0

Ulrich Schallmoser - Private Veräußerungsgeschäfte bei grundbesitzenden vermögensverwaltenden Personengesellschaften

Andreas Treiber - Nach "Arex" und "Herst" - Steigender Einfluss des Zivilrechts der Mitgliedstaaten auf unionsrechtliche Rechtsbegriffe?

Christoph Wäger - Sein und Nichtsein bei fehlender Rechtsfähigkeit: Bruchteilsgemeinschaft und Mehrwertsteuergruppe

Werner Widmann - $\$ 25 f$ UStG als Produkt kodifizierter Rechtsprechung 


\section{Otto Schmidt online}

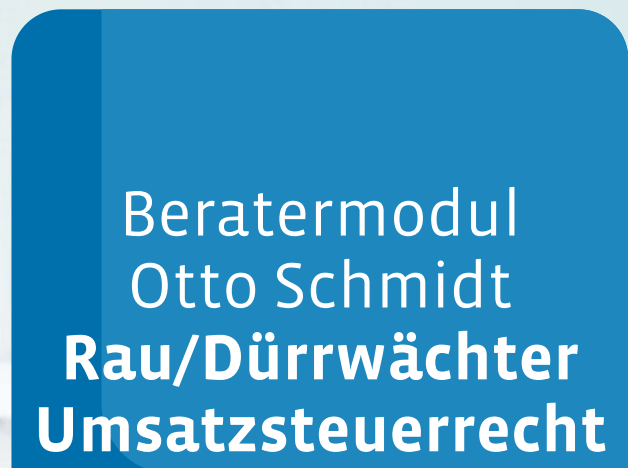

Birenteld

Das große

Handbuch

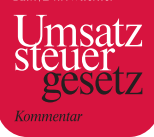

UStG

Stadie

Kommentar
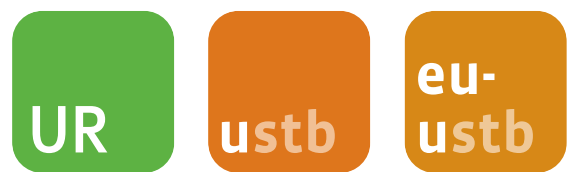

Profitieren Sie von kontinuierlich aktualisierten Premium-Inhalten:

> Einer der führenden Großkommentare zum Umsatzsteuergesetz, vierteljährlich umfassend aktualisiert

$>$ Meinungsbildend und tiefgehend

$>$ Rechtssicherheit und Zitierfähigkeit

$>$ Praktische Suchfunktionen, Filtermöglichkeiten und Vorschlagslisten

$>$ Inklusive Selbststudium mit Zertifikat nach § 15 FAO

Nur 72,- $€$ monatlich für 3 Nutzer.

Auch im Aktionsmodul Steuerrecht enthalten.

\section{Jetzt 4 Wochen gratis nutzen!}

www.otto-schmidt.de/ukm-modul 